\title{
TH!NK: A Framework to Assess and Support Critical and Creative Thinking
}

\section{Dr. Anita Vila-Parrish, North Carolina State University}

Anita R. Vila-Parrish is the Director of the Undergraduate Program and Teaching Assistant Professor in Edward P. Fitts Department of Industrial and Systems Engineering at North Carolina State University. Before returning to graduate school, Anita worked in global new product operations at Dell Computers which afforded her the opportunity to travel and work closely with colleagues in Europe, Asia, and Latin America to launch laptop products worldwide. Anita received her PhD in Industrial Engineering at NCSU in 2010 and has since expanded her research in inventory optimization to include engineering education. Her experiences as an engineer have motivated the work done in this study as well as others that aim to improve the success of students entering the global landscape. She teaches the industry-sponsored capstone design course which has led to a second stream of research focused on developing methods to model problem-solving during capstone design.

\section{Dr. Tameshia Ballard Baldwin, North Carolina State University}

Dr. Tameshia Ballard Baldwin is a Teaching Assistant Professor working jointly in the College of Engineering and in the Department of STEM Education within the College of Education at North Carolina State University. She earned a B.S. in Biological Engineering from North Carolina State University and an M.S. and Ph.D. in Biological Systems Engineering from Virginia Polytechnic Institute and State University. Dr. Baldwin's primary focus is working across the Colleges of Engineering and Education on engineering education related initiatives. She teaches undergraduate courses in the First Year Engineering Program and in the Department of STEM Education. Dr. Baldwin's research interests include selfefficacy, motivation and persistence of underrepresented populations in STEM and engineering design in $\mathrm{K}-12$.

\section{Dr. Lina Battestilli, North Carolina State University}

Lina Battestilli is Teaching Assistant Professor of Computer Science at NC State University. She received her Ph.D. in Computer Science from NCSU in August 2005, her masters in Computer Networking in August 2002 also at NCSU and her BS in Electrical Engineering and Minor in Applied Mathematics from Kettering University in 1999.

Prior to joining North Carolina State University, Dr. Battestilli was a network research engineer at the Next Generation Computing Systems at IBM Research. She worked on the PowerEN Technology, a blur between general purpose and networking processors and hardware accelerators. She identified and studied workloads at the edge of the network that required high-throughput and fast deep-packet processing.

Her research interests include the transformation of Datacenter networking to support Cloud Computing, Software Defined Networking, Openflow, techniques and uses of Deep Packet Processing, scale-out architectures, advanced scheduling of network resources, Control \& Management plane design and development. Dr. Battestilli's is also interested in innovation in Computer Science Education, especially via the use of Cloud Computing Technology.

\author{
Ms. Hailey Queen, North Carolina State University \\ Dr. Jessica Young Schmidt \\ Dr. Susan Carson, North Carolina State University
}




\title{
TH!NK: A Framework to Assess and Support Critical and Creative Thinking
}

\begin{abstract}
:
This work in progress study describes a strategic university initiative (TH!NK) that is aimed at improving critical and creative thinking throughout the undergraduate curricula. The TH!NK initiative is part of the North Carolina State University's five year Quality Enhancement Plan (QEP). This initiative is designed to train faculty to utilize strategies that cultivate students' critical and creative thinking in the classroom. TH!NK provides a comprehensive framework for implementing strategies that support higher-order thinking skills through faculty training, mentoring, and formal assessment of student learning outcomes. In TH!NK courses, students are introduced to and given opportunities to evaluate their own work and that of others using the intellectual standards of critical thinking which include clarity, accuracy, precision, relevance, significance, depth, breadth, logic, and fairness. In addition, students become familiar with standards for judging creative thinking such as originality, appropriateness, flexibility, and contribution to the domain. Student learning outcomes include the application of critical and creative thinking skills and intellectual standards in the process of solving problems.
\end{abstract}

TH!NK began its second year in August 2015 with a cohort of approximately 40 faculty participating from across the university including computer science and first year engineering (FYE). In the first year of the TH!NK program, student learning outcome assessment data was collected using multiple methods. One method was the Critical Thinking Assessment Test (CAT) developed by researchers at Tennessee Tech University that was administered in a pre- and postassessment format at the beginning and end of the semester. Statistical analysis showed that there were significant gains in courses that used pedagogical approaches that emphasized critical and creative thinking multiple times throughout the semester. Faculty also design a discipline-specific assignment that would be assessed using the TH!NK Common Rubric, a modified version of the Association of American Colleges and Universities' Value Rubrics.

The second year of the TH!NK initiative focused on first year courses, with an increased emphasis on first year engineering courses. Four faculty, two from the computer science department and two from the FYE program, are taking part in this second iteration of the initiative, resulting in substantial changes to the way they teach and assess their students. During the planning process in the summer 2015, it became evident that while these courses offered opportunities for students to work on projects, tools for assessing the students' thinking were not extensively used. Specifically, prior to TH!NK while student artifacts were assessed, the design processes themselves were not assessed, and therefore students only received constructive feedback on work products, not work process. With the required TH!NK course revisions, there is an opportunity to improve the students' thinking process which in turn should improve the quality of their final solution. The goal of this work-in-progress research project is to explore how emphasizing critical and creative thinking skills in the first year engineering were implemented in four engineering classrooms.

\section{Motivation}


The recent poll by the Association of American Colleges and Universities (AAC\&U) of 305 employers revealed that the ability to think clearly about complex problems, to analyze a problem to develop workable solutions, to be creative and innovative in solving problems, and to apply knowledge and skills in new settings are among the most desirable traits in recent college graduates (Hart Research Associates, 2007). There is no doubt that these expectations are critical for STEM majors who are entering the ever-changing, high-tech workforce as well as those pursuing academic careers. In the Engineer of 2020 (2004), the National Academy of Engineers (NAE) highlighted the importance of education that prepares students for a rapidly changing, global, technologically advanced, and innovative workplace. In order to be successful in such an environment the NAE outlined the characteristics of the future engineer. Among these characteristics are strong analytical skills, practical ingenuity, creativity, agility, and flexibility.

Creative work in most disciplines is more than having eccentric or unique thoughts, but also requires the "creator" to raise vital questions, to gather relevant information, to generate multiple ideas (multiple possible hypotheses, multiple solutions, multiple interpretations, etc.), to interpret and evaluate information, and to draw appropriate conclusions (Ennis, 1985; Csikszentmihalyi, 1996). While it is clear that critical and creative thinking skill development in undergraduate education are national STEM priorities, there is ample evidence that many adults, including college students, consistently fall prey to flawed and biased thinking. (Halpern, 1998; Kahneman, 2011; Kahan et al, 2013) The good news is that critical and creative thinking skills are not limited to the few geniuses who are "born with it"; these higher-order thinking skills can be developed through practice, feedback, and reflection. (Miri, 2007; Sawyer, 2013).

In order to build the STEM workforce of tomorrow, faculty must be trained to implement evidence-based pedagogies that foster higher-order thinking skills. Specifically, learning environments must foster and support critical and creative thinking skills. While there are countless examples of institutions focusing faculty development efforts on promoting critical thinking, very few place an explicit emphasis on the creative aspect of higher-order thinking. The singular example we identified that emphasized critical and creative thinking was focused in the liberal arts (Five Colleges of Ohio, 2012). Higher education must shift the paradigm that often does not explicitly emphasize creative and critical thinking in lower level courses but then holds the expectation that students will be prepared for the higher-order thinking required in the capstone senior design or project-based courses where students often struggle with the process (Atman et al. 2005). These initiatives must be widespread, spanning curricula in STEM from freshman to senior level courses.

\section{Background}

Currently, the TH!NK initiative at a North Carolina State University (NCSU), is part of the university's five year Quality Enhancement Plan (QEP). This initiative is designed to train faculty to utilize evidence-based strategies that cultivate students' critical and creative thinking in the classroom. TH!NK provides a comprehensive framework for implementing strategies that support higher-order thinking skills through faculty training, mentoring, and formal assessment of program goals. While many faculty may have an awareness of evidence-based teaching approaches, there is more limited evidence that this awareness translates into appropriate implementation (Henderson and Dancy, 2009). The TH!NK program aims to fill the translation gap, enabling 
faculty to successfully transform their classrooms to support critical and creative thinking. In TH!NK courses, students are introduced to and given opportunities to evaluate their own work and that of others using the intellectual standards of critical thinking which include clarity, accuracy, precision, relevance, significance, depth, breadth, logic, and fairness. In addition, students become familiar with standards for judging creative thinking such as originality, appropriateness, flexibility, and contribution to the domain. Student learning outcomes include the application of critical and creative thinking skills and intellectual standards in the process of solving problems.

We have already undertaken transforming a number of courses that primarily serve firstsemester, first-year undergraduates as part of the QEP. Since the focus of the QEP was on courses serving first-year students, the implementation has been in courses such as first-year writing, general education courses, introductory biology, introductory chemistry as well as introduction to engineering. Over forty faculty members have already participated in TH!NK training, revised their courses, and have implemented new pedagogical strategies. Faculty who have undergone TH!NK training for their first year courses report greatly increased use of teaching strategies that promote higher-order thinking, and $93 \%$ of faculty report that participation in the training impacted the way they teach their other courses as well.

Preliminary student learning outcome assessment data points to students meeting or exceeding the predetermined expectations at the end of the first semester on activities that were scored using the common rubric described in the assessment section of this paper. We also are able to observe increasing trends in the Critical Thinking Assessment Test (described in the assessment section), and in some cases, large, statistically significant increases over one semester (Carson 2015a).

The second year (Fall 2016 to Spring 2016) of the TH!NK initiative is focused on first year courses, with an increased emphasis on first year engineering courses. Four faculty, two from the computer science department and two from the FYE program, are taking part in this second iteration of the initiative, resulting in substantial changes to the way they teach and assess their students. During the planning process in the summer 2015, it became evident that while these courses offered opportunities for students to work on projects, tools for assessing the students' thinking were not extensively used. Specifically, prior to TH!NK while student artifacts were assessed, the design processes themselves were not assessed. With the required TH!NK course revisions, there is an opportunity to improve the students' thinking process which in turn should improve the quality of their final solution and allow faculty additional opportunity for feedback.

\section{TH!NK Student Learning Outcomes \& Assessment Structure}

The primary student learning outcome we aim to achieve through the initiative is for students to apply critical and creative thinking skills and behaviors in the process of solving problems and addressing questions. As previously mentioned, the AAC\&U value rubric (full rubric available at Carson, 2015b) was used to assess critical and creative skills listed in Table 1.

Table 1: Skills assessed by the Common Rubric.

\section{Raising questions, formulating problems}




\begin{tabular}{|l|}
\hline Articulating the issue and its scope \\
\hline Gathering and assessing relevant information \\
\hline Selecting and analyzing information \\
\hline Influence of context and assumptions \\
\hline Synthesizing and generating ideas \\
\hline Combining elements or ideas in ways that are coherent and logical \\
\hline Embracing contradictions \\
\hline Generating and judging alternatives \\
\hline Originality of thought \\
\hline Adaptability and flexibility of thought \\
\hline Considering alternatives and reaching reasoned conclusions \\
\hline Judging appropriateness \\
\hline Taking intellectual risks \\
\hline Effectively communicating \\
\hline Abstract thinking or Relating the "Big Idea" \\
\hline Communication \\
\hline
\end{tabular}

In total, student learning outcomes will be assessed by three primary methods.

1. The common rubric will be applied in each TH!NK course to a discipline-specific, coursespecific assignment designed by the instructor. We will discuss the common rubric activity used by four engineering faculty in the following section in detail.

2. Because the "rubric assignment" in each course will be different, an additional measure of student higher-order thinking will be employed using the Critical Thinking Assessment Test (CAT) developed at Tennessee Technological University through an NSF grant (Stein et al, 2006). The CAT was given at the beginning of each course and then again at the end of the semester in order to measure gains. This assessment cannot be utilized on its own to measure our outcomes because it offers limited information on creative thinking and metacognition, and lacks the opportunity for students to receive feedback on discipline-specific work.

3. Students self-assessed their metacognitive habits at the start of their first year and at the end of each TH!NK course. The survey is comprised of a subset of the relevant questions in the Metacognitive Awareness Inventory (Schraw and Dennison, 1994), as well as program specific reflections that ask students to consider the degree to which they made gains in incorporating habits over the course of the semester.

A summary of the assessment methods and timeline are provided in Table 2.

Table 2. Student Learning Outcome Assessment Timeline.

\begin{tabular}{|c|c|c|}
\hline $\begin{array}{c}\text { Student Assessment } \\
\text { Tool }\end{array}$ & Description and Method & When Administered \\
\hline
\end{tabular}




\begin{tabular}{|c|c|c|}
\hline $\begin{array}{l}\text { Common Rubric } \\
\text { Applied to the Capstone } \\
\text { Assignment in each } \\
\text { course }\end{array}$ & $\begin{array}{l}\text { Faculty score course- } \\
\text { specific student assignments } \\
\text { (or a randomly selected } \\
\text { sample of assignments if } \\
\text { large section) using the } \\
\text { common rubric. }\end{array}$ & $\begin{array}{l}\text { EACH COURSE: Students complete } \\
\text { the assignment to be assessed toward } \\
\text { the end of each TH!NK course }\end{array}$ \\
\hline $\begin{array}{l}\text { CAT (Stein et al, 2006) } \\
\text { Critical Thinking } \\
\text { Assessment Test }\end{array}$ & $\begin{array}{l}\text {-Standardized test of critical } \\
\text { thinking } \\
\text {-Assessment Personnel } \\
\text { administers and proctors }\end{array}$ & $\begin{array}{l}\text { PRE: start of the course } \\
\text { POST: end of the course }\end{array}$ \\
\hline $\begin{array}{l}\text { Online Self-Assessment } \\
\text { of metacognitive habits }\end{array}$ & $\begin{array}{l}\text {-Email survey } \\
\text {-Students complete out-of- } \\
\text { class }\end{array}$ & $\begin{array}{l}\text { PRE:start of the course } \\
\text { POST: at the end of each TH!NK course }\end{array}$ \\
\hline
\end{tabular}

In the following sections we will describe the engineering courses that implemented the initiative in the Fall of 2015 with a focus on what course changes were made as a result of the pedagogical training. We will also discuss some preliminary results and future work.

\section{E 101: Implementation of TH!NK in Engineering \& Problem Solving}

E 101: Introduction to Engineering \& Problem Solving is an introductory course that all first year engineering students take in their first semester. Two sections implemented the initiative and are included in this study. The course is taught in sections of 45 to 60 students and some of its objectives include introducing students to engineering as a discipline and profession, introducing and engaging students in the engineering design cycle, and improving student professionalism and communication. The course structure is as follows:

- Students attend a practicum session for the first five weeks of the course that introduces them to various university and college-level academic policies.

- After week 5, students transition from the practicum to a 110 minute lab section taught once a week by instructors in the College of Engineering.

As a part of E 101, students are required to implement the engineering design process in the completion of a design project with content from various engineering disciplines. Students work in teams of four on one of fourteen available design projects for the last eight weeks of the semester. Examples of design projects that students can choose from include a hovercraft, rube goldberg machine, collapsible bridge, concrete canoe and a fabric bucket. Each project has a research component and a set of design constraints that the students must adhere to. The project culminates in Freshman Engineering Design Day (FEDD), an annual event where students showcase their design projects and compete for awards.

For the purposes of this work in progress study, we will focus on the course changes aimed at improving and assessing critical and creative thinking behaviors. Before the larger design project in E101, several new assignments were created and a number of strategies were employed in order to scaffold critical and creative thinking skills throughout the course. The 
first strategy was the implementation of critical thinking scenarios. In some cases, students were presented with data and asked to interpret and draw conclusions based on that data. In other instances, they were tasked with accepting or refuting a scientific claim based on presented information. While in others they were given a conclusion and asked what data or information they would need to verify that claim. The intent of these exercises was to impress upon students the importance of applying critical thinking skills in the analysis of information upon which critical decisions are often made, particularly in the engineering profession. The classroom was abuzz with discussion during these exercises, as students were clearly engaged in the activity.

Another course change involved a class period focused solely on creativity, how it's defined, standards used for judging creative thinking and the behaviors that constitute creative thinking. Students completed several TTCT (Torrance Test of Creative Thinking) creativity exercises that measure creativity primarily by discrete, non-judgmental tasks that focus on fluency of thought, flexibility of thought, originality of thought and elaboration on one's own thinking. These activities were followed up by a discussion of creativity in engineering design. The instructor of the second section provided opportunities for small group and individual creative problem solving throughout the semester. In both sections, students were encouraged to keep the principles of creativity in mind as they worked through their design projects.

\section{E101 Common Rubric Assignment}

While some differences existed in the strategies employed in both sections the common rubric assignment was the same. Students' prior experiences with critical and creative thinking exercises in both sections exposed them to the type of thinking that they would need to apply to be successful in their design project experience. In previous years, students have been asked to summarize their design project experience through the creation of a short video highlighting how the engineering design process was implemented, the design challenges encountered and how those were overcome, and advice for next year's freshmen. While valuable, this assignment alone did not allow for evaluation of the critical and creative thinking skills outlined in the common rubric. Therefore, students were asked to provide a separate written reflection of their experiences working on the design projects. Rather than give the students free rein in their reflections, we thought it more useful to prompt them through the following questions:

- Did you, as an individual, come up with more than one design idea when working on the project? How did you decide on which idea(s) to share with your team?

- Did your original design idea(s) change after listening to your teammates' ideas? If so, in what ways did they change?

- Were there any ideas that you or your team initially deemed "bad" ideas that you ended up using? Or were there any "good" ideas that you got rid of? Explain why.

- Describe the process your team went through to narrow down ideas and arrive at a final project design. What factors did your team consider when deciding on the final design?

- What steps of the engineering design process did you find most difficult to implement and why?

- What new information did you learn from your research on the project? Did that new information have an impact on the final project design? If so, describe the impact. 
- Upon evaluating other teams' projects at FEDD, was your team's design original? If not, what specific things could your team have done to improve originality while still working within the design constraints of the problem?

- What could you, as an individual, have done differently to increase the success of your team in completing the design project? Provide specific examples.

\section{E101 Common Rubric Ratings: Preliminary Results for Section 1}

Students seemed to perform best on common rubric items: embracing contradictions, generating and judging alternatives and adaptability and flexibility of thought. Generally, the majority $(>60 \%)$ of students fell in the "emerging" (rating=2) and "developed" (rating=3) categories for most of the criteria outlined in the common rubric with the exception of items: articulating the issue and its scope, selecting and analyzing information, influence of context and assumptions and taking risks. It was interesting to note that all students rated poorly (rating=1) for rubric items selecting and analyzing information and influence of context and assumptions.

$76 \%$ of students demonstrated "emerging" ability to combine ideas in ways that were coherent and logical. It was particularly encouraging that the majority of students $(64 \%)$ exhibited "developed" skills as it relates to embracing contradictions while all students demonstrated either "emerging" or "developed" skills in generating and judging alternatives. Students were effective at exploring alternative ideas, but often failed to clearly identify criteria for judging those ideas. In addition, all students rated in the 2 and 3 categories for adaptability and flexibility of thought. Students were generally open to new design ideas and willing to make necessary changes when needed. They seemed to recognize and value diverse perspectives in the design process, which is an essential viewpoint for them to develop early in their engineering careers.

\section{E101 Common Rubric Ratings: Preliminary Results for Section 2}

The majority of students in the second section of E 101 are also part of a selective academic program on campus called the University Scholars Program. This should be considered when comparing these results to the results in other courses and sections who may have students with a wider variety of academic credentials.

The majority (>70\%) of students in the course fell into the "emerging" (rating=2) and "developed" (rating=3) categories for the majority of the twelve areas of evaluation described in the common rubric. The areas of learning in which students demonstrated the highest level of understanding were in: articulating the issue and its scope, communication, adaptability and flexibility of thought, and generating and judging alternatives. Student scores in the areas of adaptability and flexibility of thought along with generating and judging alternatives were especially encouraging because the great majority of students (96\% and $92 \%$ respectively) were able to demonstrate an "emerging" level of understanding or higher. Additionally, in both of these categories some students exhibited a "capstone" level of understanding.

Students scores were weakest in the following areas: selecting and analyzing information, influence of context and assumptions, and taking risks. After assessing all areas of evaluation it was the learning area of selecting and analyzing information where students scored weakest overall, with nearly $30 \%$ of students showing little/no evidence" (rating=1) and no students demonstrating more than an emerging understanding $($ rating $=2)$ in this area. This is likely a 
reflection of the project itself, the questions asked in the project reflection, and the students' limited exposure to applying research in practice.

\section{CSC113 Intro to Computing Matlab}

CSC113 Intro to Computing Matlab is a large course ( 150 students) which is offered both fall and spring semester. The students are mainly mechanical and aerospace engineering freshmen and sophomores and this class fulfills their introduction to programming course requirement. The course structure is as follows:

- All students attend twice a week a 50 minute lecture in a large auditorium led by a computer science faculty member.

- The students are divided into groups of about 30 and attend a weekly $2 \mathrm{hr}$ and 45 minutes hands on lab session led by lab instructors who are undergraduate students who have previously taken the class.

\section{CSC113 Common Rubric Assignment}

Typically in this course the projects are programming assignments that are very well defined and give little to interpretation. In fact, we run automated grading tests on the student's' code in order to make sure that that they have completed the program correctly. These types of programming assignments assess the student's ability for precision and logic but leave very little for individual expression and creativity. Grading is not subjective and students must learn some pre-defined learning objectives in order to receive a good grade.

In the real-world, software engineers need to often engage in code review to ensure high-quality. Code review is a process where computer code is inspected by other programmers, with the intention of finding bugs and improving code readability. In order to have student experience that in the classroom, we added a code review Lab assignment. Students teams swapped their code and reviewed it for clarity, accuracy, logic, originality, relevance (key standards of the critical and creative process). The students were given a rubric so that they can comment on code style and functionality. Upon reviewing someone else's code, the students were asked to reflect on how they would improve for future coding assignments.

As part of the TH!NK program, we added an additional project to the course which was much more open-ended in nature and focused on evaluating the student's creative process and thinking. We gave the students the option to pick one of two programs to write: Adventure Game or Connect-4. We only gave them the basic requirements for their programs and encouraged them to be creative and come up with their own more unique and advanced requirements. Basically, with this project the students were led through the software engineering cycle of gathering requirements, design, development and testing.

In order to evaluate the student's thinking process in completing this project we had them complete the following milestones:

- Milestone 1: Initial design with their unique requirements

- Milestone 2: A week after the project was first assigned we gave the students an additional requirement and asked them to incorporate it in their design. This gave the 
students experience with agile software engineering where requirements change as the project moves along. It forced them to re-evaluate their design and adapt.

- Final Submission: The students had to submit a final design, visual flowcharts, testing plan, documentation and their code.

- Reflection: Each student was also asked questions to reflect on the execution of the project. They had to highlight issues, what they had learned, what changes they had to make, alternative designs, etc.

It was interesting to see the students' response to this programming assignment. As expected, there was a great variability of produced programs. Some students really got into it and created very elaborate games versus other students did the absolute minimum. In the students' reflections though mostly everyone commented positively on the open-endedness of the project and enjoyed being given the place to explore and be creative.

\section{CSC113 Common Rubric Preliminary Results}

A random sample of 25 students were graded using the Common Rubric. The majority of the students scored in the range of "emerging" (rating =2) to "developed" (rating =3) in most categories. However, for some of the categories there were large percentages of students that did poorly and got "little/no evidence" (rating=1). For example, there were $44 \%$ students that that received rating of 1 for the generating and judging alternatives. Once, the students had come up with a design they never consider any other alternatives. They students also had low scores in abstract thinking. They focused on the details but were unable to relate the "big idea" behind their project. For this course, 64\% of the students got a rating of 3 for "Combining elements of ideas in ways that are coherent and logical", which is to be expected in a programming assignment.

\section{CSC116: Introduction to Computing - Java}

CSC116 is a critical path course for the computer science (CSC) major; it is the first CSC course that CSC majors are required to take. The course structure is as follows:

- Each on-campus section of the course meets for 110 minutes twice a week in an integrated lecture lab.

- Each section has a max of 33 students based on the size of the computer lab and the number of available computers.

Each section of the on-campus course has two undergraduate TAs who attend lecture, answer questions during lecture, answer questions on the message board, hold office hours, and grade projects, homeworks, in-class exercises, tests/exams.

Similar to the strategy used in CSC 113 we implemented code peer review and then selfreflections. The reflections gave the students a chance to think about the projects as more than just code and to reflect on their process of completing the projects.

\section{CSC116 Common Rubric Assignment}

During the Fall 2015, the instructor added a Comprehensive Exercise to CSC116, which was assessed using the common rubric. During one of the last days of class, students spent the full 
class period (110 minutes) working on the comprehensive exercise in assigned pairs. The students applied the concepts that they learned throughout semester in CSC116 going from requirements and design to implementation and testing. Along with showing the students that they had learned a great deal during the semester, the exercise was also meant to give students an idea of what was to come in the next course (CSC216).

For the common rubric assignment, each team was given a description of an idea that their client would like to see implemented. The students were told that the client expects their work to be well thought out and implemented. We gave the students an ordered set of work items that they would complete during the class period:

1. Keep a journal/log of thought process and decisions made while working on the exercise, include alternative approaches you consider. [Note that students started the journal in step 1 but continued to add to it throughout the class period.]

2. Write a detailed problem description. [Requirements]

3. Write a black-box test plan. [Testing]

4. Determine the classes that your implementation will use. [Design]

5. Determine the methods for each class. [Design]

6. Determine the attributes of each class. [Design]

7. Refine your design. Write headers for all methods, but do not implement the methods. [Design]

8. Let the teaching staff know that you have completed design. You will be assigned another group to discuss your designs.

9. Complete the implementation (with documentation) using a text-based user interface. [Implementation]

10. Test your implementation. [Testing]

Given the time limit of 110 minutes, most groups did not get to the implementing and testing portions of the exercise. Students were not to begin coding until they had completed steps 1-8. Halfway through the class period, the instructor gave each group an extension that the client expected to be included within the design and implementation. The extension was given to see how well students' plans would adapt to changing requirements. At the end of the class period, students individually completed a self-reflection survey that helped us to access the exercise using the common rubric as it made the students describe some of their thought process and allowed us to ask about the difficulty of the exercise and whether it helped them understand the materials.

\section{CSC116 Common Rubric Preliminary Results}

The instructor completed the comprehensive exercise in her three sections of CSC116, which contained 78 students. 25 students' work were randomly selected for assessment using the common rubric. Examining the survey responses for the 78 students, when asked the degree of difficulty they associated with this exercise, $75.64 \%$ of the students stated difficult or very difficult and $20.51 \%$ of the students stated average. The fact that the students found the assignment difficult was not a surprise to the instructor as the assignment was extremely different from the other assignments in the course and required the students to do more critical and creative thinking. While the students found the exercise difficult, $78.21 \%$ of the students thought the exercise helped them to see how all topics covered in CSC116 fit together, and $89.74 \%$ of the students thought the exercise helped them to understand designing a 
program/application. The responses for the helpfulness of the exercise were very motivating for continuing to have similar exercises in future semesters. Examining the results of the common rubric assessment, the students performed best with two rubric items: (a) Combining elements or ideas in ways that are coherent and logical and (b) Adaptability and flexibility of thought. For these two rubric items, a major of the students received twos. When designing classes and methods for a coding program, it is essential that students can combine elements in a coherent and logical manner.

\section{Overall Results and Preliminary Conclusions}

The overall results for the Common Rubric Assignments for all four classrooms is shown in Figure 1. It shows that first year students demonstrated emerging (rating=2) ability in most of the criteria in the rubric. Very few students reached the capstone level (rating=4). In order to develop the students' critical and creative thinking, courses and assignments have to be carefully designed to cover the skills listed in Table 1. With continued exposure to TH!NK strategies in subsequent courses, it would be interesting to study in future work if students could reach the capstone level.

Figure 1. Overall Results for the Common Rubric

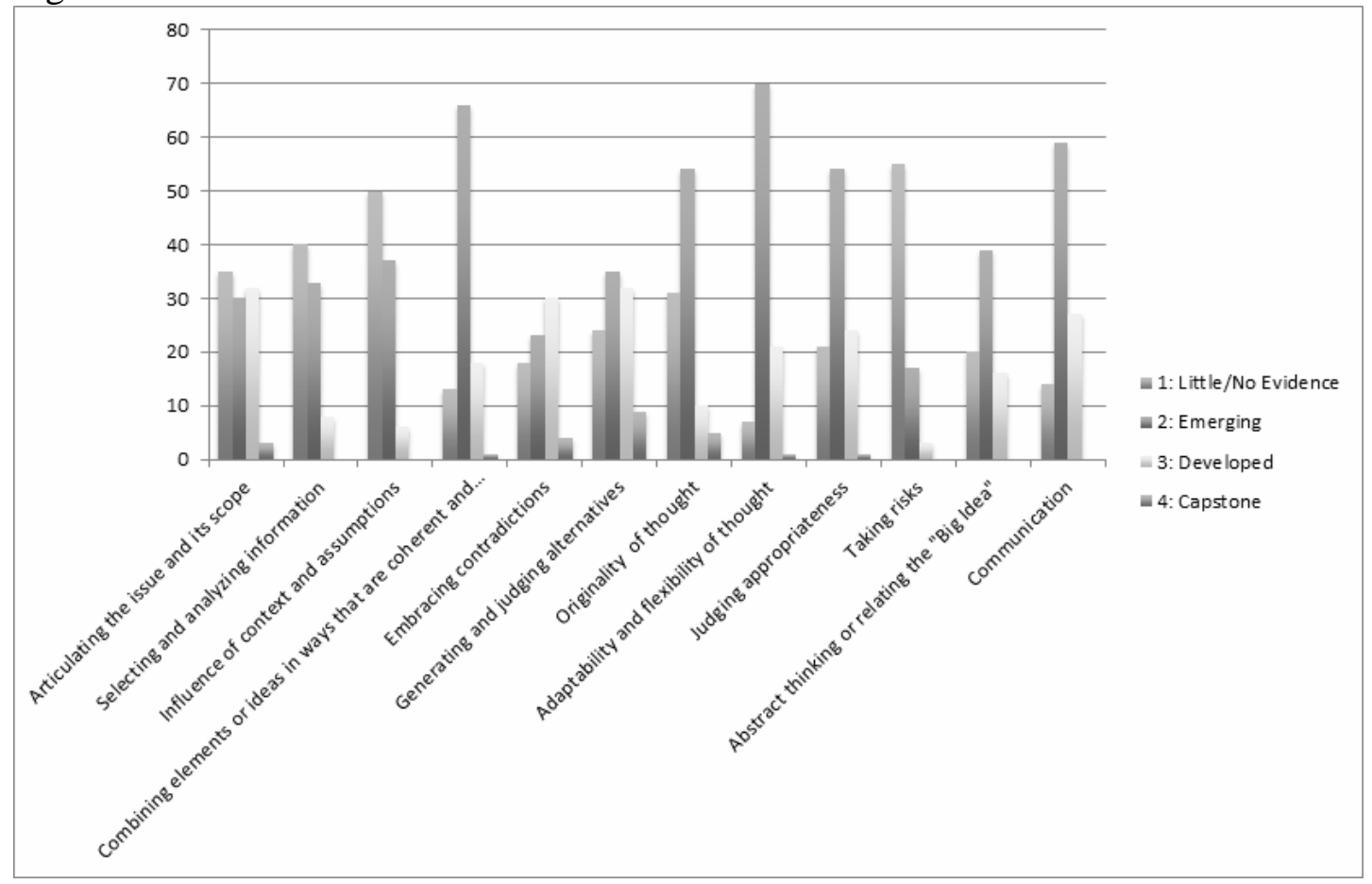

\section{Next Steps}

This work in progress paper describes the implementation of the TH!NK initiative in four engineering classrooms at NCSU. We have focused on the key elements of the program and on the design and preliminary results related to the common rubric assignment in each course. Since the results for the common rubric activity were recently gathered the next steps include analyzing the results more critically. We are interested in identifying common strengths and 
weaknesses across the first year engineers as assessed by the common rubric activities. We are also interested in triangulating these results with the results of the CAT.

\section{References}

1. Atman C.J., M.E. Cardella, J. Turns, and R. Adams. 2005. Comparing freshman and senior engineering design processes: An in-depth follow-up study, Design Studies, 26, 325--357.

2. Carson, S. 2015a. Targeting critical thinking skills in a first- year undergraduate research course. JMBE. 16(2): 148--156.

3. Carson, S. 2015b.

4. http://think.dasa.ncsu.edu/wp-content/uploads/sites/20/2015/09/Common-Rubric-2015-for-website.pdf. Accessed 12/17/2015.

5. Csikszentmihalyi, M. 1996. Creativity: Flow and the Psychology of Discovery and Invention. Harper CollinsPublishers. New York, NY.

6. Ennis, R. 1985. The logical basis for measuring critical thinking skills. Educational Leadership. 43(2): 44-48 .

7. Five Colleges of Ohio and Teagle Foundation. 2012. Creative and critical thinking: Assessing the foundations of a liberal arts education. 3-Year Comprehensive Report. Retrieved from http://imaginativecurriculumnetwork.pbworks.com/f/CREATIVE+AND+CRITICAL+THINKING+LIBER AL+ARTS+EDUCATION.pdf

8. Halpern, D. F. 1998. Teaching critical thinking for transfer across domains. American Psychologist, 53(9):449--455.

9. Henderson, C. and M. Dancy. 2009.Impact of physics education research on the teaching of introductory quantitative physics in the United States. Phys. Rev. ST Phys. Educ. Res. 5, 020107.

10. Kahan, D.M., E. Peters, E.C. Dawson, and P. Slovic. 2013. Motivated Numeracy and Enlightened SelfGovernment. Yale Law School, Public Law Working Paper No. 307. Available at SSRN: http://ssrn.com/abstract=2319992 or http://dx.doi.org/10.2139/ssrn.2319992

11. Kahneman, D. 2011. Thinking, Fast and Slow. Farrar, Straus and Giroux. ISBN-10: 0374275637

12. Miri, B., D. Ben-Chaim, U. Zoller. 2007. Purposely teaching for the promotion of higher-order thinking skills:a case of critical thinking. Res Sci Educ. 37: 353--369.

13. National Academy of Engineering. 2004. The Engineer of 2020: Visions of Engineering in the New Century.The National Academies Press. Washington, DC.

14. Sawyer, K. 2013. Zig Zag: The Surprising Path to Greater Creativity. Jossey-Bass. San Francisco, CA.

15. Schraw, G. and R. Dennison. 1994. Assessing metacognitive awareness. Contemporary Educational Psychology. 19, 460--475.

16. Stein, B., A. Haynes, and M. Redding. 2006. Project CAT: Assessing Critical Thinking Skills. Proceedings of the National STEM Assessment Conference. NSF and Drury University. 
